\title{
USO DA CALCULADORA NOS ANOS INICIAIS DO ENSINO FUNDAMENTAL: concepções dos futuros professores
}

\author{
USE OF THE CALCULATOR IN THE EARLY YEARS OF \\ ELEMENTARY EDUCATION: concepts of future teachers
}

\author{
USO DE LA CALCULADORA EN LOS AÑOS INICIALES DE LA ENSEÑANZA \\ PRIMARIA: concepciones de los futuros profesores
}

\author{
Keli Cristina Conti \\ Professora Doutora da Faculdade de Educação ( $\mathrm{FaE})$ da \\ Universidade Federal de Minas Gerais (UFMG). \\ Belo Horizonte - MG, Brasil. \\ keli.conti@gmail.com \\ Mariana Lima Vilela \\ Mestranda em Educação e Docência pela Universidade Federal de Minas Gerais (UFMG). \\ Professora substituta de Matemática do Colégio Técnico da UFMG. \\ Belo Horizonte - MG, Brasil. \\ marianalima@ufmg.br
}

Nayara Katherine Duarte Pinto

Mestranda em Educação e Docência pela Universidade Federal de Minas Geais (UFMG). Professora designada de Matemática pela Secretaria de Educação de Minas Gerais. Belo Horizonte - MG, Brasil. nayarakatherine@hotmail.com

Resumo: A calculadora está presente no nosso cotidiano de diversas formas, porém há certa resistência quando mencionamos o seu uso no ambiente educacional, especialmente nos Anos Iniciais do Ensino Fundamental. Diante disso, propusemos uma oficina com estudos e práticas, com os discentes do curso de Pedagogia da Universidade Federal de Minas Gerais, ou seja, futuros professores que ensinarão Matemática nos Anos Iniciais do Ensino Fundamental, ressaltando a importância da utilização correta da calculadora nesta etapa de ensino. $O$ objetivo desta pesquisa qualitativa foi investigar e analisar as concepções prévias e posteriores às atividades dos futuros professores sobre o uso da calculadora nos Anos Iniciais. A mesma integra um projeto de pesquisa em desenvolvimento intitulado "Contribuições do Laboratório de Ensino de Matemática para a formação inicial do professor que ensina Matemática". Para essa vertente da pesquisa apoiamos em Selva e Borba (2010), Lopes e Rodrigues (2009) e nos Parâmetros Curriculares Nacionais (PCN/BRASIL, 1997), entre outros documentos e autores. Apresentaremos neste trabalho o que pensavam os futuros professores sobre o uso da calculadora, as atividades propostas com essa ferramenta tecnológica, as reflexões e ressignificações dos mesmos sobre a temática. Após a análise dos dados coletados, constatamos que a maioria dos futuros professores passou a apoiar o uso da calculadora neste nível de ensino.

Palavras-chave: Matemática. Anos Iniciais do Ensino Fundamental. Calculadoras. Formação Inicial de Professores.

\begin{abstract}
The calculator is present in our daily life in several ways, but there is some resistance when we mention its use in the educational environment, especially in the Early Years of Elementary Education. Therefore, we proposed a workshop with studies and practices with the students of the Pedagogy course of the Federal University of Minas Gerais, the future teachers who will teach Mathematics in the Early Years of Elementary Education, emphasizing the importance of using the calculator correctly at this stage of education. The objective of this qualitative research was to investigate and analyze the pre and post conceptions of the activities of the future teachers about the use of the calculator in the Early Years. It integrates a research project under development entitled "Contributions of the Mathematics Teaching Laboratory for the initial formation of the teacher who teaches Mathematics". In this aspect of the research, we support Selva and Borba (2010), Lopes and Rodrigues (2009) and National Curricular Parameters (PCN / BRASIL, 1997), among other documents and authors. We are presenting in this work what the future teachers thought about the use of the calculator, the activities proposed with this technological tool, the reflections and re-significances of the them about the subject. After analyzing the data collected, we found that most of the future teachers started to support the use of the calculator at this level of education.
\end{abstract}

Keywords: Mathematics. Early Years of Elementary Education. Calculators. Initial Teacher Training.

Resumen: La calculadora está presente en nuestro cotidiano de diversas formas, pero hay cierta resistencia cuando mencionamos su uso en el ambiente educativo, especialmente en los Años Iniciales de la Enseñanza Primaria. Por lo 
tanto, hemos propuesto un taller para el estudio y la práctica, con los estudiantes de la Facultad de Educación de la Universidad Federal de Minas Gerais, los futuros profesores que enseñarán matemáticas en los primeros años de la educación primaria, resaltando la importancia del uso correcto de la calculadora en este paso de enseñanza. El objetivo de esta investigación cualitativa fue investigar y analizar las concepciones previas y posteriores a las actividades de los futuros profesores sobre el uso de la calculadora en los Años Iniciales. Esta integra un proyecto de investigación en desarrollo titulado "Contribuciones del Laboratorio de Enseñanza de Matemáticas para la formación inicial del profesor que enseña Matemáticas". Para esta vertiente de la investigación apoyamos en Selva y Borba (2010), Lopes y Rodrigues (2009) y en los Parámetros Curriculares Nacionales (PCN / BRASIL, 1997), entre otros documentos y autores. Presentaremos en este trabajo lo que pensaban los futuros profesores sobre el uso de la calculadora, las actividades propuestas con esa herramienta tecnológica, las reflexiones y resignificaciones de los mismos sobre la temática. Después del análisis de los datos colectados, constatamos que la mayoría de los futuros profesores pasó a apoyar el uso de la calculadora en ese nivel de enseñanza.

Palabras clave: Matemáticas. Años Iniciales de la Escuela Primaria. Calculadoras. Formación Inicial de Profesores.

\section{INTRODUÇÃO}

O uso da calculadora está presente na nossa rotina, como por exemplo, quando usamos as calculadoras de bolso, nos celulares e computadores, mas pouco presente na sala de aula. Atualmente, muitos professores e pais ainda veem o uso da calculadora na escola como algo errado e com ideias de que prejudicaria o desenvolvimento dos estudantes na aprendizagem das operações básicas ou que "ficariam preguiçosos".

Conscientes que os futuros professores, em breve envolvidos diretamente num debate que tem argumentos a favor e contra o uso de calculadoras nas salas de aula dos Anos Iniciais, resolvemos fazer um estudo com os discentes do curso de Pedagogia ${ }^{1}$ da Universidade Federal de Minas Gerais (UFMG). Desta forma, nossos objetivos foram investigar as concepções, anteriores e posteriores a abordagem didática proposta pelas autoras, dos futuros professores sobre o uso das calculadoras e apresentar as atividades desenvolvidas na disciplina Fundamentos e Metodologia de Ensino de Matemática I, referente ao tema.

No início deste trabalho exibiremos algumas notas a favor do uso desse instrumento na sala de aula dos Anos Iniciais do Ensino Fundamental, na sequência as concepções dos participantes do estudo. Mais adiante descreveremos as atividades desenvolvidas em conjunto com os estudantes e as ressignificações dos mesmos posteriores a essas atividades. Por fim, faremos algumas considerações sobre como essa prática contribuiu para o debate do uso de calculadoras nesta etapa da Educação Básica.

\section{USO DA CALCULADORA}

Embora o uso cotidiano das calculadoras na sociedade seja frequente, ainda há certa resistência, quando mencionamos o seu uso no ambiente educacional e em especial nos Anos Iniciais do Ensino Fundamental.

O uso da calculadora tem sido recomendado pelos Parâmetros Curriculares Nacionais (BRASIL, 1997) em várias situações, assim como o uso de computadores e outros materiais, destacando seu importante papel no processo de ensino e aprendizagem, considerando que o acesso a elementos como a calculadora e computadores, "já é uma realidade para parte significativa da população" (BRASIL, 1997, p. 34).

O documento reforça que os usos de calculadoras "precisam estar integrados a situações que levem ao exercício da análise e da reflexão, em última instância, a base da atividade matemática" (BRASIL, 1997, p. 19) e também defende seu uso como um instrumento que traria contribuições para o ensino de Matemática:

Estudos e experiências evidenciam que a calculadora é um instrumento que pode contribuir para a melhoria do ensino da Matemática. A justificativa para essa visão é o fato de que ela pode ser usada como um instrumento motivador na realização de tarefas exploratórias e de investigação (BRASIL, 1997, p. 34).

\footnotetext{
1 Uma versão preliminar reduzida desta proposta foi apresentada no III Congresso de Inovação e Metodologias no Ensino Superior i9 com $5 \mathbf{c}-\mathbf{2 0 1 7}$ (CIM).
} 
De acordo com Selva e Borba (2010), o uso deste instrumento na sala de aula, suscita confrontos, em especial quando se trata dos Anos Iniciais do Ensino Fundamental:

Algumas defesas do uso da calculadora são embasadas no amplo uso dessa ferramenta em situações matemáticas de fora da sala de aula e o fato de que calculadoras simples são acessíveis às diferentes camadas da sociedade. Um argumento desfavorável é o de que crianças novas, que ainda não aprenderam a realizar as operações aritméticas, não devem ser expostas ao uso da calculadora, pois deixarão, assim, de aprender a realizar as contas básicas - com números naturais e números racionais - envolvidas em problemas matemáticos (SELVA; BORBA, 2010 p. 10).

Ainda nesse sentido, sobre o uso da calculadora, destacamos alguns mitos e medos, de acordo com Van de Walle (2009), em grande parte baseados na pouca informação a respeito:

a) Se as crianças usarem calculadoras, elas não aprenderão os "fundamentos";

b) As calculadoras tornam os estudantes preguiçosos;

c) Os estudantes devem aprender o "modo real" antes de usar calculadoras;

d) Os estudantes se tornarão dependentes demais de calculadoras. (Van de Walle, 2009, p. 131-132)

Concordamos com Van de Walle (2009), que "em vez de temer o dano potencial que as calculadoras podem causar, é importante compreender como as calculadoras podem contribuir para a aprendizagem da Matemática" (VAN DE WALLE, 2009, p. 130).

Consideramos que uma abordagem correta da calculadora pode subsidiar o desenvolvimento dos estudantes com as operações e o raciocínio lógico, bem como podem ser usadas para desenvolver conceitos e para fortalecer a resolução de problemas, são usadas nas práticas sociais e também podem economizar tempo (VAN DE WALLE, 2009). Para que uma calculadora encontre o resultado correto é necessário ser manipulada pelo ser humano, havendo um raciocínio antecipado para a realização das operações e nesse sentido "a calculadora será usada como recurso, não para substituir a construção de procedimentos de cálculo pelo aluno, mas para ajudá-lo a compreendêlos" (BRASIL, 1997, p. 45). Isso também é reforçado por Van de Walle (2009), ao expressar "quando usadas adequadamente, as calculadoras aumentam a aprendizagem; elas não atrapalham 0 caminho da aprendizagem" (VAN DE WALLE, 2009, p. 132).

Lopes e Rodriguez (2009) enfatizam que se utilizada corretamente contribui para o desenvolvimento de competências de cálculo, que são de acordo com os autores: calculadora, estimativa, cálculo mental e cálculo escrito. Os autores apresentam a ilustração (Figura 1) de uma mesa para reforçar a importância do equilíbrio entre as competências. Cada "pé da mesa" representaria uma competência.

Figura 1 - Competências de cálculo

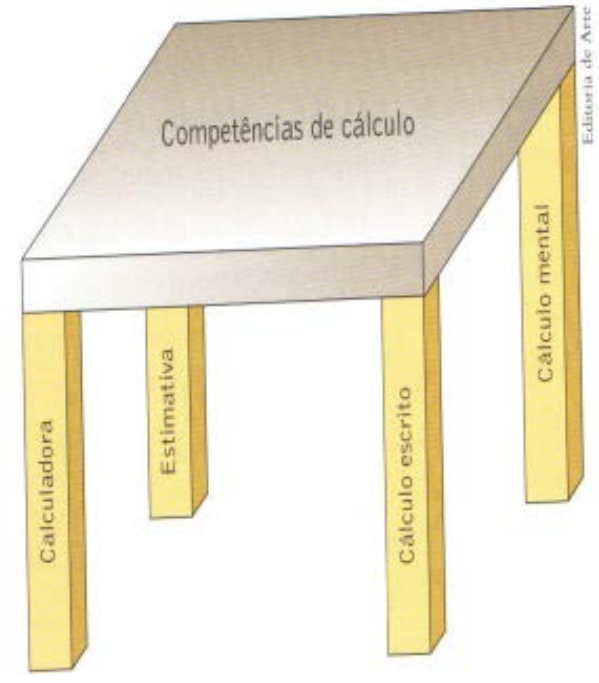

Fonte: Lopes e Rodriguez (2009, p. 147). 
De acordo com Lopes e Rodriguez (2009), boas propostas com o uso de calculadoras potencializariam "a capacidade dos alunos de fazer, mais e melhor, cálculo mental e estimativa, bem como ajudam a compreender o que fazem (às vezes mecanicamente) no cálculo escrito" (LOPES; RODRIGUEZ, 2009, p. 147).

Lopes e Rodriguez (2009) também apresentam que uma justificativa antiga para não se usar a calculadora na escola era a do custo. Atualmente isso não se justifica, pois é possível adquirir uma calculadora simples "pelo preço de uma passagem de ônibus municipal" (LOPES; RODRIGUEZ, 2009, p. 148).

Selva e Borba (2010) defendem que nem sempre o uso da calculadora proporciona explorações conceituais. As autoras ressaltam que para alcançar esse objetivo, são necessárias situações didáticas bem planejadas, com procedimentos bem selecionados. Como a calculadora não opera por si mesmo, é preciso criar ambientes no qual os estudantes precisem decidir quais os procedimentos deverão tomar para resolver determinados problemas.

Conscientes de que o principal responsável pelo uso, ou não, desse instrumento na sala de aula é o professor é que propusemos um estudo com o objetivo de investigar as concepções dos futuros professores sobre o uso da calculadora nos Anos Iniciais do Ensino Fundamental. Inicialmente descrevemos as concepções iniciais, para posteriormente apresentar algumas propostas de atividades e reflexões.

\section{PESQUISA REALIZADA COM FUTUROS PROFESSORES}

Muitas vezes a questão do uso (ou não) da calculadora em sala de aula, de acordo com Selva e Borba (2010) pode ser "em parte, consequência da formação que o(a) professor(a) vivenciou em sua graduação" (SELVA; BORBA, 2010, p. 15). Concordando com as autoras, propusemos uma oficina com estudos e práticas, com os discentes do curso de Pedagogia da Universidade Federal de Minas Gerais (UFMG), futuros professores dos Anos Iniciais do Ensino Fundamental (1. ${ }^{\circ}$ ao $5 .^{\circ}$ ano). Participaram, nas duas fases da abordagem, 37 estudantes de duas turmas do curso noturno.

A pesquisa foi desenvolvida numa abordagem qualitativa (BOGDAN; BIKLEN, 1994). Optamos por esta abordagem a fim de valorizar todos os dados qualitativos (descrição detalhada de situações, contextos, pessoas, interações, comportamentos, as falas dos futuros professores, atitudes, concepções, pensamentos, entre outros) como importantes e preciosos para assegurar o compromisso com a produção de conhecimento. Ela integra um projeto de pesquisa em desenvolvimento intitulado "Contribuições do Laboratório de Ensino de Matemática para a formação inicial do professor que ensina Matemática" que visou ampliar o Laboratório de Ensino de Matemática (LEM) na Faculdade de Educação (FaE/UFMG), e busca analisar e interpretar práticas de formação e de atuação de futuros professores de forma a compreender e ressaltar a importância de um LEM para a formação inicial do professor que ensinará Matemática e seu reflexo no processo de ensino e aprendizagem dos estudantes. Nesse sentido, uma das vertentes da pesquisa tem sido sobre o uso da calculadora e em especial, sobre as concepções dos futuros professores que ensinarão Matemática nos Anos Inicias do Ensino Fundamental.

\subsection{O que pensavam os futuros professores sobre o uso da calculadora}

Inicialmente foram propostas algumas reflexões a respeito do período em que os futuros professores frequentavam os Anos Iniciais do Ensino Fundamental, com o objetivo de conhecer saberes que foram apropriados durante a trajetória como estudante da Escola Básica. Nesse sentido a maioria deles, relatou que não se lembravam do uso ou que não era permitido, como por exemplo, as situações a seguir:

"Quando eu estava no Ensino Fundamental minhas professoras não me deixavam nem sequer tocar em uma calculadora. (...) e se me pegassem com uma, eu iria direto para a diretoria" (Futura Professora $\mathrm{B}^{2}$ ).

"Lembro que não usava calculadora na escola e aprendi como uma coisa 'errada' a se fazer" (Futura Professora D.).

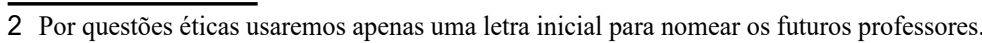


USO DA CALCULADORA NOS ANOS INICIAIS DO ENSINO FUNDAMENTAL: concepções dos futuros professores | Keli Cristina Conti; Mariana Lima Vilela; Nayara Katherine Duarte Pinto

"Na minha experiência escolar, não utilizamos calculadora em sala (a não ser a científica no Ensino Médio)" (Futura Professora C.).

"Na minha época escolar, nos anos iniciais não era permitido o uso de calculadoras, ou aparelhos semelhantes. Hoje acompanhando meu irmão na escola vejo que ele também não utiliza" (Futura Professora C. A.).

Posteriormente foi solicitada aos futuros professores a seguinte reflexão:

1. O que você pensa sobre o uso de calculadoras nas aulas de

2. Matemática dos Anos Iniciais do Ensino Fundamental?

3. O que costumam pensar as famílias dos alunos?

4. Em que atividades poderiam usar?

Quanto às respostas à primeira questão, classificamos as mesmas em três grupos.

a) Totalmente favoráveis ao uso da calculadora;

b) Totalmente contrários ao uso da calculadora;

c) Consideram o uso interessante, mas com ressalvas;

No gráfico 1 a seguir, apresentamos a quantidade de pessoas classificadas em cada um dos grupos.

Gráfico 1 - Concepções iniciais do futuros professores

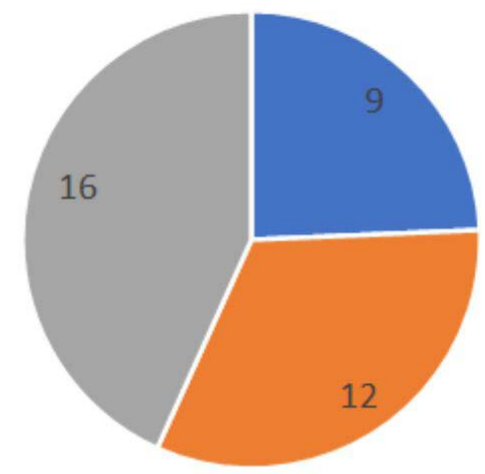

- Totalmente favoráveis ao uso da calculadora

- Totalmente contrários ao uso da calculadora

n Consideram o uso interesante, mas com ressalvas

Fonte: Elaborado pelas autoras.

Quanto às respostas classificadas no item "a", totalmente a favoráveis ao uso da calculadora obtivemos 9 respostas. Classificamos como contrários ao uso da calculadora (item b), 12, das respostas obtidas. Para este grupo foi frequente a preocupação com o prejuízo cognitivo que a calculadora poderia trazer.

Entre os que classificamos como favoráveis, mas com ressalvas, foram 16 (item c). Neste grupo foram frequentes expressões que nos fizeram concluir serem favoráveis ao uso após o domínio pleno das operações. Como por exemplo: "acho interessante, uma vez que ele saiba bem como fazer todas as operações, as tabuadas, etc" (Futuro Professor R.).

Sobre a segunda questão: "O que costumam pensar as familias dos alunos?". Embora 7 participantes não tenham se posicionado sobre isso, a grande maioria, 27 deles, afirmou que a família discordaria do uso da calculadora e muitos deles, de acordo com os futuros professores, argumentando que o professor não estaria comprometido com a aprendizagem das crianças como foi 
expressado pelo Futuro Professor R. " acredito que pensam que o professor não ensina corretamente ou que está com preguiça de fazer o seu trabalho. Ou pensam que com o uso de uma máquina seus filhos podem ficar preguiçosos, não aprenderem todas as operações perfeitamente". Além disso, a Futura Professora M. ponderou "a família pode considerar que as calculadoras atrapalham 0 processo de aprendizagem".

Ainda sobre a questão da família, dois futuros professores concluíram que resistentes, as famílias poderiam ser convencidas com um bom projeto de utilização. Um dos futuros professores também achou que a família, em geral não tem opinião formada e outro, concluiu que a família vai se posicionar conforme a metodologia que julgam melhor: tradicional ou construtivista. E por último também tivemos um futuro professor que concluiu que "as famílias não se preocupam com o uso exagerado das calculadoras e permitem esse uso indiscriminado" (Futura Professora I.).

Referente à terceira questão: "Em que atividades poderiam usar?" das 37 pessoas apenas 6 não sugeriram atividades, no qual uma delas justificou "preciso conhecer melhor a função das calculadoras para afirmar em quais atividades elas poderiam ser usadas" (Futura Professora A). As demais respostas, 31 estudantes, sugeriram mais de uma atividade por resposta, sendo assim, devido a diversidade das sugestões optamos por não subdividir em grupos, mas destacar algumas respostas, como essa: "usar em gincanas, atividades complementares, como por exemplo, brincar de supermercado, lojinha de departamento, ou banco em retirada e entrada de dinheiro ou então mostrar a fração dos números, e outras" (Futura Professora M.). Além disso, houve resposta como: "A calculadora poderia ser utilizada em atividades em grupos ou em jogos em sala de aula" (Futura professora D) e "em resolução de problemas com mais de uma operação, longas e complexas, para tirar provas, etc" (Futura Professora F.). Mesmo com as sugestões interessantes, elas nos pareceram genéricas, como por exemplo, "em grupos ou jogos" ou "para tirar provas", revelando indícios de que ainda não possuíam ideias mais fundamentadas a respeito do uso.

\section{PROPOSTAS DE ATIVIDADES E REFLEXÕES}

Após coletarmos as concepções iniciais dos futuros professores sobre o uso da calculadora nos Anos Iniciais, apresentamos as potencialidades do uso da calculadora nesta etapa de ensino, apoiadas nos referenciais teóricos de Imenes e Lellis (1997) e Lopes e Rodriguez (2009) e posteriormente por meio de atividades que exigiam o uso diferenciado da calculadora. Para o desenvolvimento das propostas foi utilizado o Laboratório de Ensino de Matemática (LEM) da instituição (Figura 2).

Figura 2 - LEM

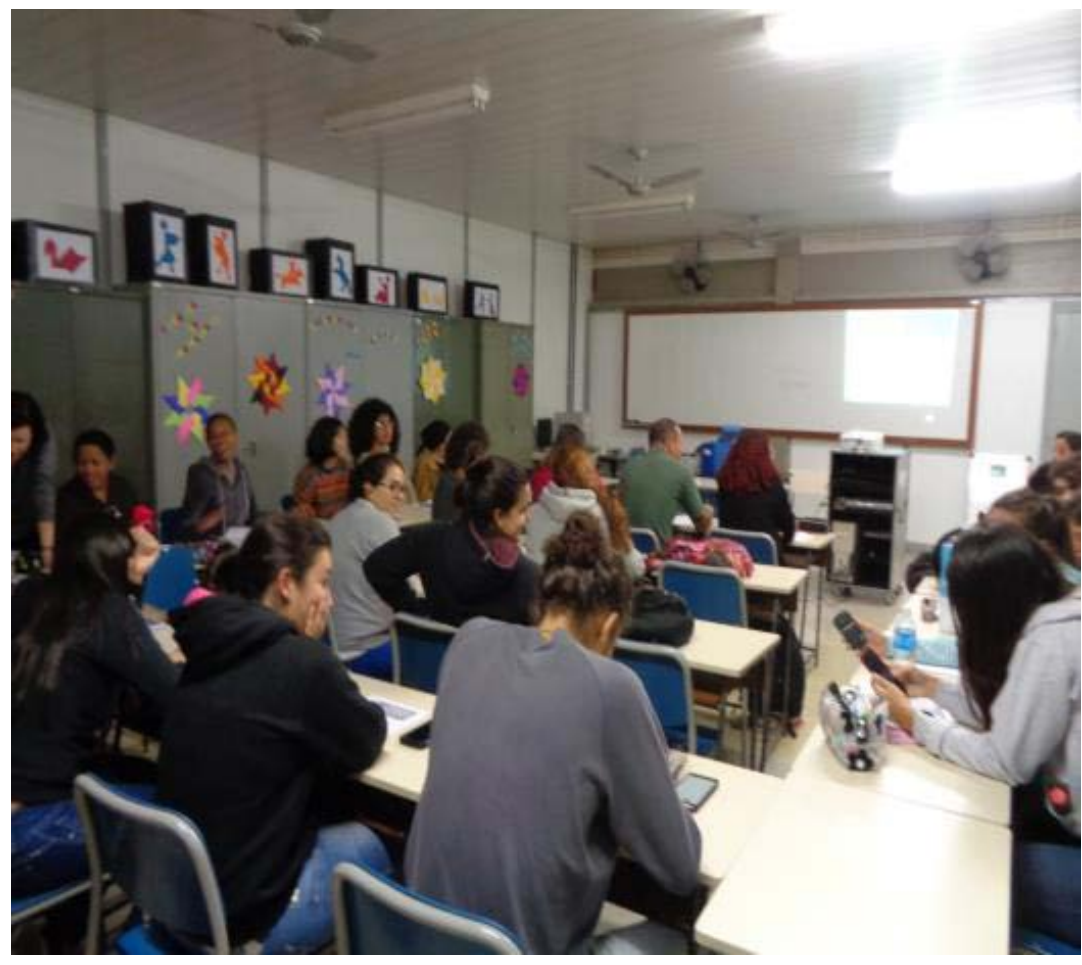

Fonte: Elaborado pelas autoras. 
Conforme Selva e Borba (2010) para que as novas concepções de ensinar e aprender sejam utilizadas na sala de aula, é necessário que sejam aprendidas pelos professores. No caso da calculadora, as autoras destacam que esse aprendizado possibilitará ao professor a utilização da calculadora de modo mais eficiente, como ferramenta potencializadora da construção do conhecimento, em suas aulas.

Selva e Borba (2010) complementam dizendo que "a mera introdução da calculadora, sem reflexão sobre suas possibilidades e seus limites, não é suficiente para essa mídia ser propulsora de desenvolvimento conceitual." (SELVA; BORBA, 2010, p. 11). Por compartilharmos com as ideias apresentadas pelas autoras, elaboramos atividades que julgamos proporcionassem aos futuros professores o aprendizado e a reflexão sobre o uso da calculadora nos Anos Iniciais do Ensino Fundamental.

De acordo com Imenes e Lellis (1997) o estudante só faz o uso correto da calculadora se sabe Matemática. Partindo dessa concepção, objetivamos despertar nos futuros professores a percepção de que atividades utilizando a calculadora, quando elaboradas com o intuito de estimular o raciocínio dos estudantes, contribui positivamente para no seu processo de aprendizado.

Ressaltamos junto aos futuros professores, que é essencial que a escola ofereça ao estudante o contato com as tecnologias e ajude-os a trabalhar com elas, mas que os estudantes devem saber calcular independentemente das máquinas e que o papel do professor é proporcionar aos estudantes o uso inteligente da calculadora, fugindo da utilização simples de conferir ou fazer contas básicas, despertando e orientando quando é necessário, ou não, o seu uso.

Também foram apresentadas aos futuros professores e discutidas as competências de cálculo conforme Lopes e Rodriguez (2009), usando a comparação da mesa com quatro pés, que são as bases para a formação do estudante, sendo elas: cálculo escrito, cálculo mental, estimativa e calculadora, já apontadas inicialmente no artigo. Se faltar uma dessas bases, o estudante não estará com as capacidades de cálculo desenvolvidas. Assim, procuramos ressaltar a importância de utilizar a calculadora nas aulas de matemática.

Antes de propormos as atividades aos futuros professores apresentamos os dois tipos de calculadora: a hierárquica (espera-se o sinal de igual para fazer os cálculos, seguindo-se a ordem - multiplicação e divisão primeiro - Ex.: $3+2 \times 4=11$ ) e a não hierárquica (Estrutura operatória não algébrica: $3+2 \times 4=20)^{3}$. Os futuros professores também tiveram oportunidade de comparar os resultados na calculadora de bolso e na calculadora do celular (Figura 3) e classificá-las como hierárquicas ou não e conhecer as funções de vários modelos de calculadoras simples (Figura 4):

Figura 3 - Futuros professores comparando as calculadoras

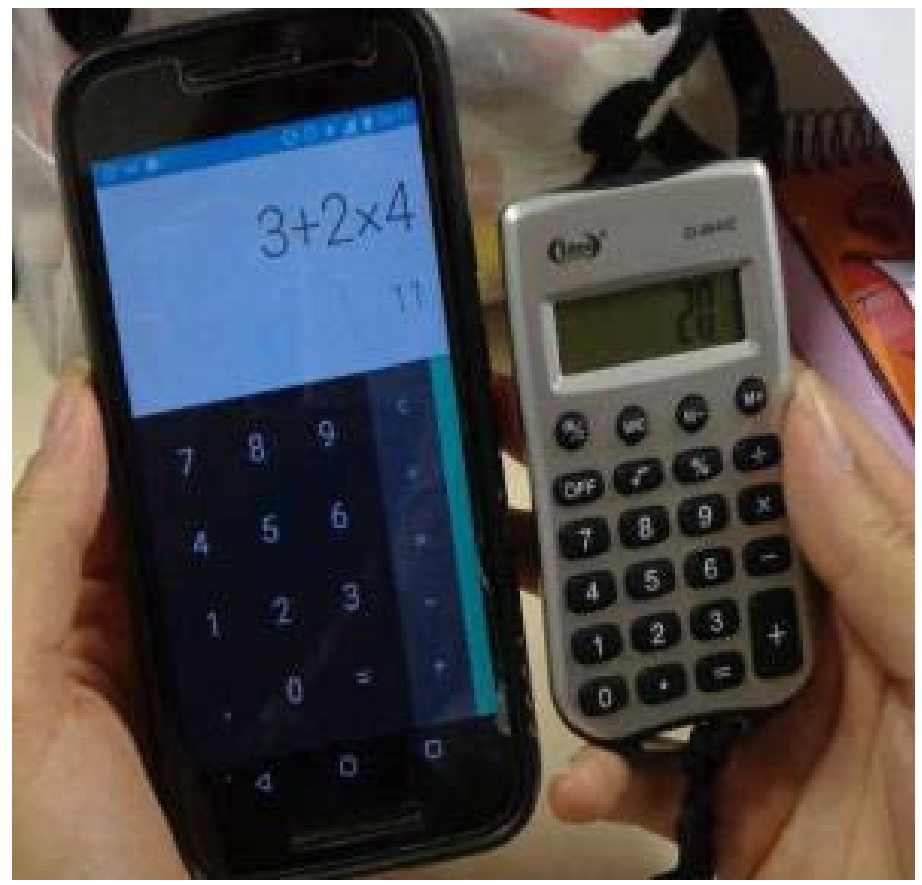

Fonte: Elaborado pelas autoras.

3 Neste caso não encontramos o resultado correto da expressão, justamente por não seguir a ordem correta na realização das operações. 
Figura 4 - Modelos de calculadoras simples

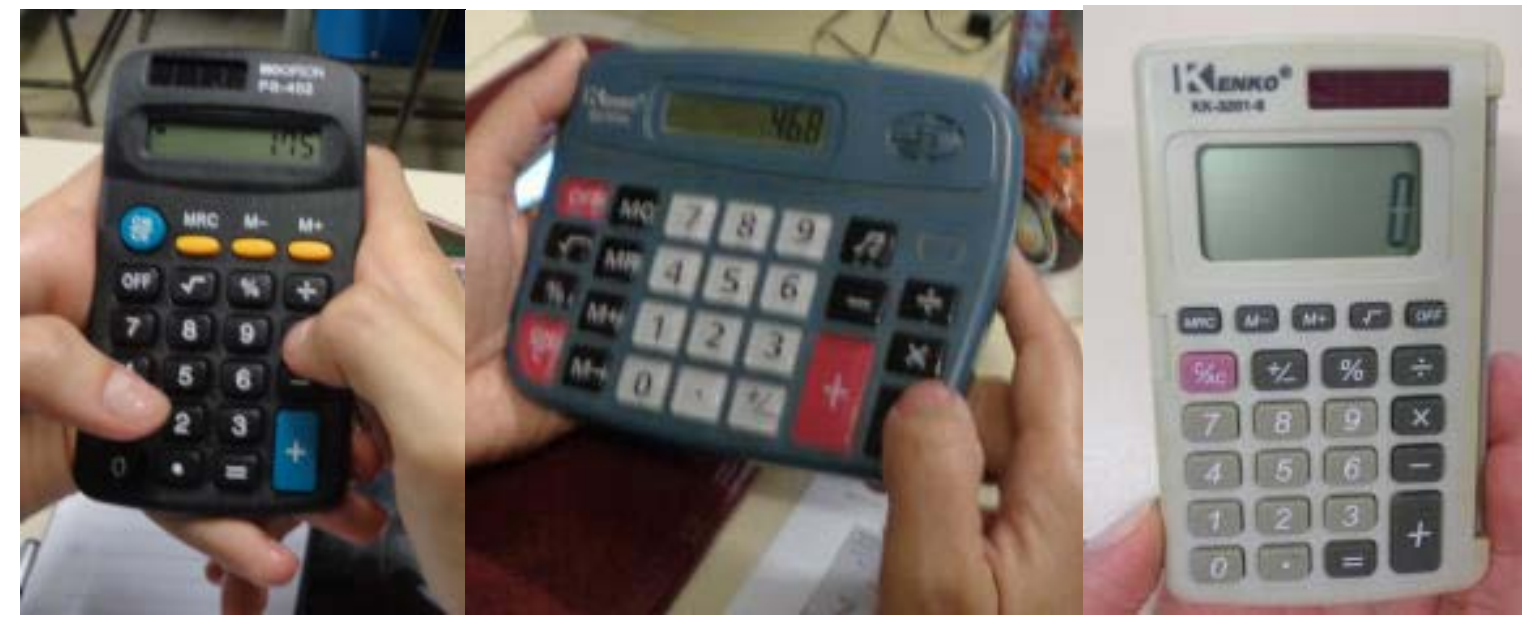

Fonte: Elaborado pelas autoras.

Outras propostas de atividades apresentadas e exploradas pelos futuros professores foram os cálculos interativos. As atividades consistiram em digitar na calculadora simples os seguintes comandos, por exemplo: " $2 \mathrm{x}=$ " (o número dois, o operador de multiplicação e o sinal de igualdade) e "4 : =" (quatro, operador de divisão e o sinal de igualdade). Repetindo sucessivamente o sinal de igualdade, os resultados obtidos foram: " $4 ; 8 ; 16 ; 32 .$. " e " $1 ; 0,25 ; 0,0625 ; 0,015625 \ldots$.., respectivamente. Com nessas respostas, foi questionado qual operação estava sendo efetuada em cada comando. Os futuros professores observaram e relataram que em " $2 \mathrm{x}=$ ", o número dois estava sendo multiplicado por dois a cada sinal de igualdade acionado. E no caso de "4 : =", notaram que o número quatro, quando acionado o sinal de igualdade, estava sucessivamente dividindo-se por quatro.

Além disso, os futuros professores tiveram a oportunidade de explorar outras funções da calculadora (Ex.: Memória aditiva: M+; Memória subtrativa: M-; Recuperar o acumulado na memória: $\mathrm{RM}, \mathrm{MR}, \mathrm{MRC}$ ou RCL, e etc.), conforme figura 5:

Figura 5 - Teclas de memória da calculadora

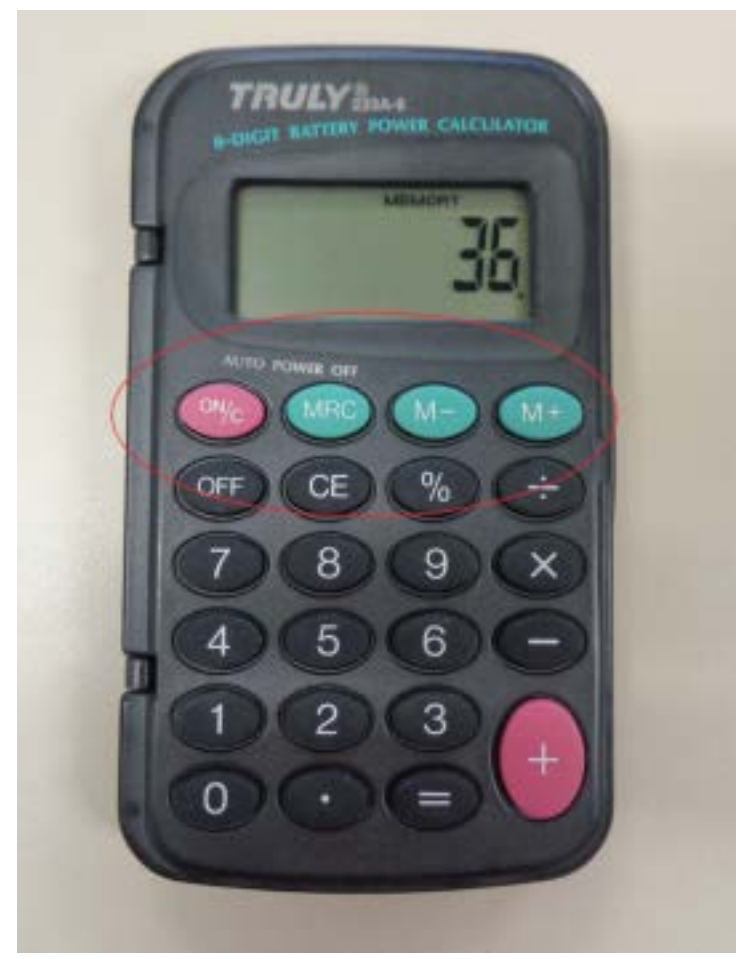

Fonte: Elaborado pelas autoras. 
A grande maioria relatou desconhecer as funções dessas teclas. Durante o momento da exploração foram intercaladas atividades que despertassem a curiosidade e conhecimento das funções da calculadora, como na Figura 6:

Figura 6 - Exemplo de atividade proposta

\begin{tabular}{|c|c|}
\hline Memória & $\begin{array}{l}\text { Hoje grande liquidação } \\
\text { LĹpis: RS I,30 } \\
\text { Bloco de papel: RS I,75 } \\
\text { Calculadorn: RS } 6,99\end{array}$ \\
\hline \multicolumn{2}{|c|}{$\begin{array}{l}\text { Suponha que você precisa comprar três dúzias de } \\
\text { lápis, } 15 \text { blocos de papel e } 18 \text { calculadoras para } \\
\text { um curso sobre "uso inteligente das } \\
\text { calculadoras de bolso". O cálculo que deve ser } \\
\text { feito para encontrar o gasto total é: }\end{array}$} \\
\hline \multicolumn{2}{|c|}{$36 \times 1,30+15 \times 1,75+18 \times 6,99$} \\
\hline \multicolumn{2}{|c|}{$36 \times 1.30=M+15 \times 1.75=M+18 \times$} \\
\hline $6.99=M+$ & $\quad 198,87$ \\
\hline
\end{tabular}

Fonte: Elaborado pelas autoras.

As "novas" discussões sobre o uso da calculadora foram baseadas nas diversas atividades propostas, cujo foco eram os Anos Iniciais do Ensino Fundamental. Nesse momento era questionado aos futuros professores quais foram os passos realizados para resolverem as atividades. Ao descreverem para toda a turma os procedimentos, os futuros professores iam percebendo que era necessário um raciocínio, que a calculadora por si só não conseguia encontrar a resposta, corroborando com as indicações de Imenes e Lellis (1997). A Figura 7 apresenta uma dessas atividades que necessita do raciocínio aritmético:

Figura 7 - Exemplo de atividade que necessita do raciocínio aritmético

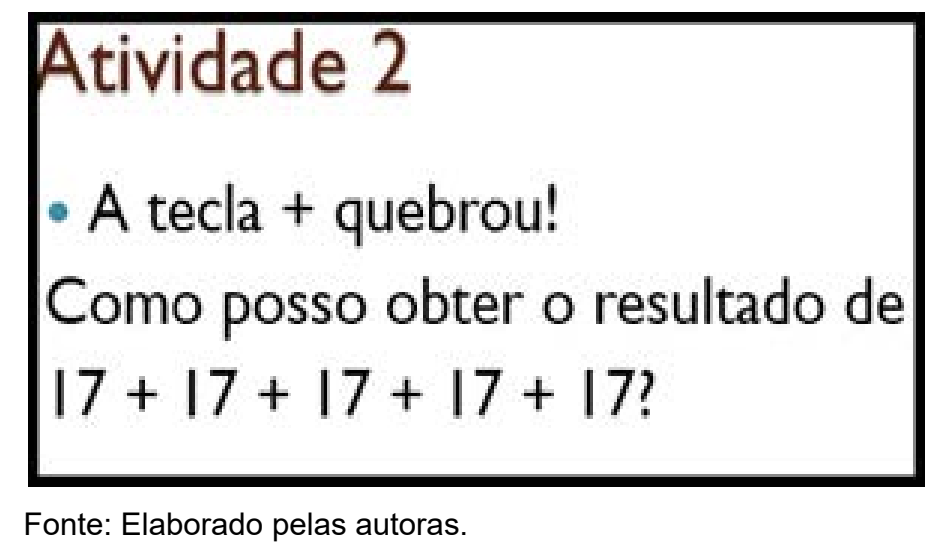

Os futuros professores também analisaram atividades propostas em livros didáticos que são destinadas ao uso da calculadora na sala de aula. Uma das propostas apresentadas, de Lopes e Rodriguez (2014) tratava do uso da estimativa e objetivava que os estudantes descobrissem a operação utilizada, como por exemplo, na situação em que usava os números 111 e 37 e que obtinha como resultado o número 3 (Figura 8). Esperava-se que o estudante do $4 .^{\circ}$ ano do Ensino Fundamental, ao ser desafiado a resolver a atividade do livro didático, antecipasse que o que se realizava era a divisão entre os números. 
Figura 8 - Uso da estimativa

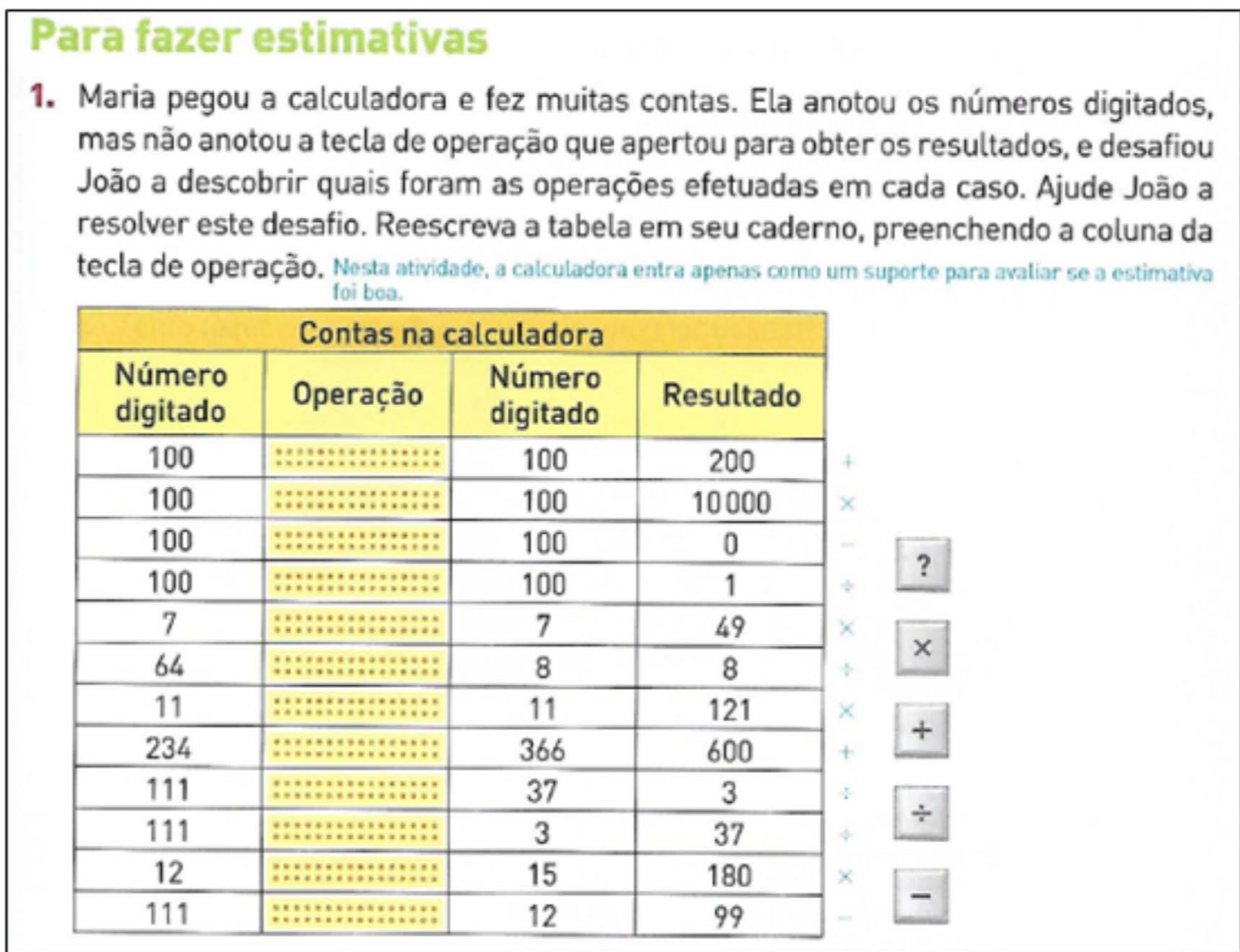

Fonte: Lopes e Rodriguez (2014, p. 225).

Além disso, foram apresentadas calculadoras diferenciadas que estão disponibilizadas na internet, como por exemplo, a Polikalc.

A Polikalc (LEANDRO, 2014) é um software educativo desenvolvido para o ensino dos cálculos aritméticos, dentre eles: o mental, com calculadora e com algoritmos exatos ou aproximados. Segue abaixo, na Figura 9, a página inicial do software educativo que disponibiliza a calculadora nas versões: "Exata", "Quebrada", "Aproximada" e "Mental":

Figura 9 - Polikak - software educativo.

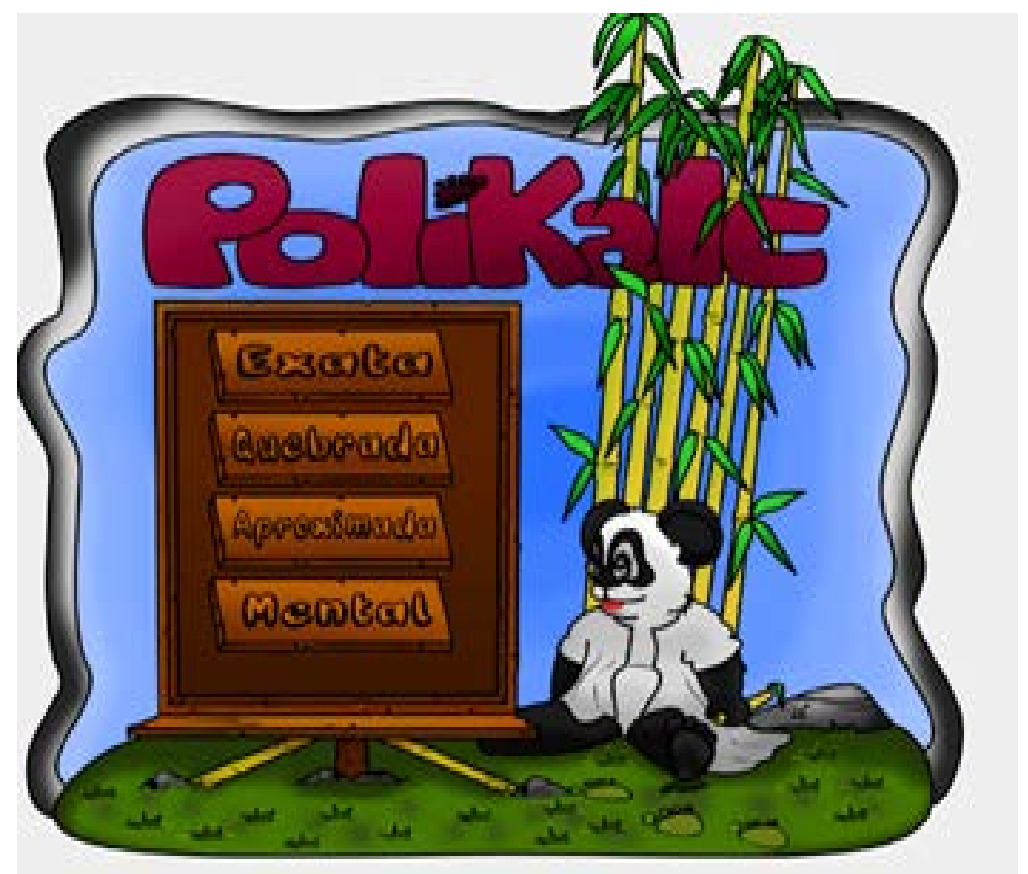

Fonte: http://polikalc.blogspot.com.br/ 
Na versão "Quebrada" da Polikalc (LEANDRO, 2014), é possível desabilitar algumas funções da calculadora, simulando a "quebra" de alguma ou algumas teclas. Com a seguinte proposta: "-A tecla "X" quebrou! Como posso obter o resultado de 4 x 39?", poderíamos ter a exploração da Polikalc - Quebrada, da seguinte forma (Figura 10):

Figura 10 - Polikalc - Versão "Quebrada"

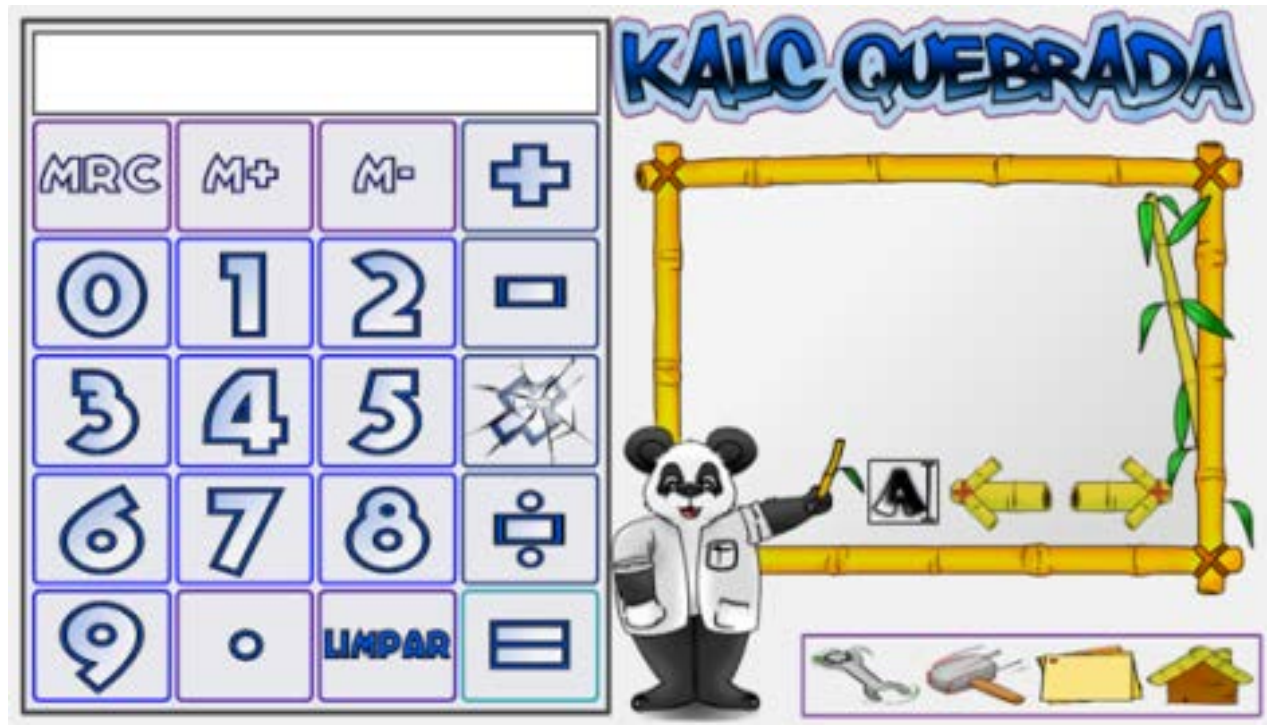

Fonte: Leandro (2014).

Em todas as versões da Polikalc (LEANDRO, 2014) estão presente um espaço para que o estudante registre seu raciocínio e que posteriormente pode ser arquivado e revisto pelo professor.

Outro recurso apresentado foi a "MusiCALcolorida" (FERNANDES et al., 2011), que pode ser aliado na introdução da calculadora e também no processo de inclusão de estudantes com deficiência visual e auditiva. É uma ferramenta elaborada para abordar, por meio de cores e música, o conceito de número real de forma multissensorial (destinada aos estudantes a partir dos Anos Finais do Ensino Fundamental). Os futuros professores também exploraram essa ferramenta, embora não tenham como foco de sua atuação, os Anos Finais do Ensino Fundamental. A Figura 11 esboça o resultado de uma operação (12/7) obtida pelo aplicativo.

Figura 11 - Resultado obtido do aplicativo MusiCALcolorida.

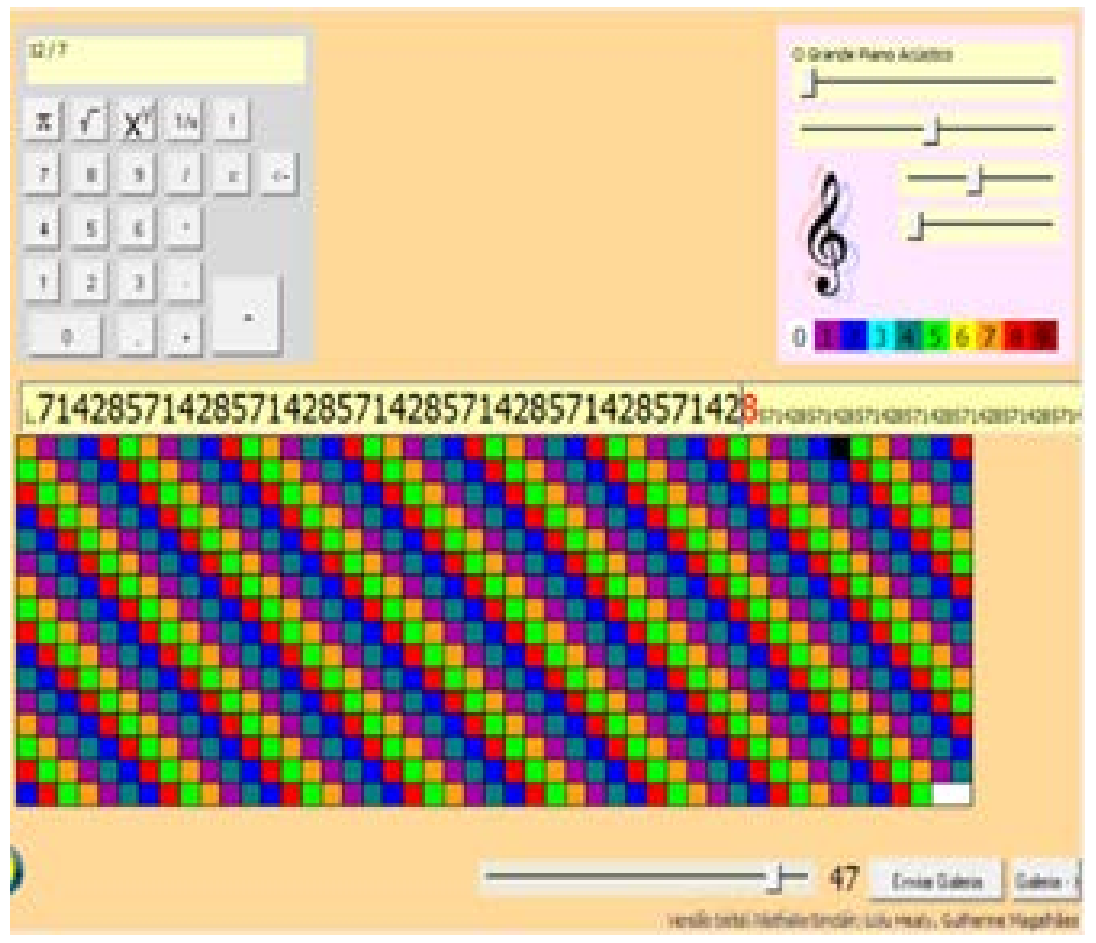

Fonte: Matemática Inclusiva (2002). 
Além dessas diversas atividades e exploração da calculadora simples e do celular, os futuros professores também tiveram a oportunidade de observar uma calculadora científica (Figura 12). Essa possui mais comandos, que permitem fazer diversas operações, no qual constam teclas que possibilita operar com as funções trigonométricas, logarítmica e outras. Porém, por apresentar um maior nível de complexidade, não incentivamos o seu uso para os anos iniciais.

Figura 12 - Calculadora científica

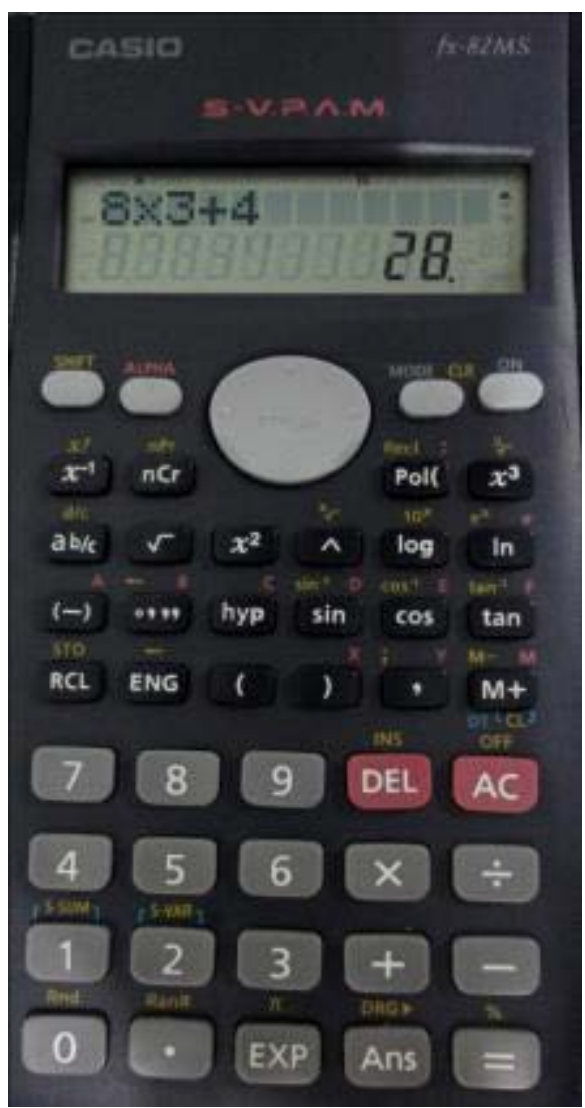

Fonte: Elaborado pelas autoras.

\section{RESSIGNIFICAÇÕES DOS FUTUROS PROFESSORES}

$\mathrm{Na}$ etapa final da aula, após os momentos relatados na seção anterior, foi proposto aos futuros professores a seguinte tarefa:

1. Elabore um pequeno texto expondo seu ponto de vista sobre o uso de calculadora nas aulas de matemática nos Anos Iniciais do Ensino Fundamental. Aborde o maior número possível de aspectos.

Nessa fase final separamos os resultados para análise de acordo com a classificação inicial descrita no item 3 deste artigo. Desta forma, a tabela 1 retrata as reclassificações dos textos do grupo "a", totalmente favoráveis ao uso da calculadora, na etapa final da aula:

Tabela 1 - Futuros professores que inicialmente foram classificados como totalmente a favor

\begin{tabular}{cc}
\hline Opinião Final & Quantidade \\
\hline Totalmente a favor & 06 \\
Totalmente contra & 00 \\
Consideram o uso interessante, mas com ressalvas & 03 \\
Total & 09 \\
\hline
\end{tabular}

Fonte: Elaborado pelas autoras.

Pelas informações da tabela 1 temos que nenhum participante passou a ser contra o uso de calculadora e seis participantes permaneceram a favor do uso da calculadora, alguns textos 
relataram que as atividades da aula contribuíram para reforçar suas opiniões iniciais, como podemos notar no trecho: "Meu pensamento sobre o uso da calculadora não mudou, já que eu era favorável, apenas foram agregados novas perspectivas de como aplicar, os tipos de atividades propostas, as formas de abordagem e as funções de uma calculadora" (Futura Professora R.).

Do grupo "a" três futuros professores continuaram concordando, mas apresentaram mais argumentos sobre os cuidados ao utilizar a calculadora em sala de aula. Por exemplo: "minha opinião continua sendo a favor do uso da calculadora, com mediação e planejamento; revisaria talvez as atividades para que fossem mais eficazes" (Futura Professora C). Com isso, do grupo "a" três futuros professores ressignificaram sua opinião final, ou seja, passaram de totalmente a favor para favorável com ressalvas.

Na Tabela 2 apresenta os resultados do subgrupo dos estudantes que estavam classificados na primeira fase como "totalmente contrários ao uso da calculadora":

Tabela 2 - Futuros professores que inicialmente foram classificados como totalmente contrários

\begin{tabular}{cc}
\hline Opinião Final & Quantidade \\
\hline Totalmente a favor & 01 \\
Totalmente contra & 02 \\
Consideram o uso interessante, mas com ressalvas & 09 \\
Total & 12 \\
\hline
\end{tabular}

Fonte: Elaborado pelas autoras.

Neste grupo, tiveram dois futuros professores que mantiveram sua opinião contrária ao uso de calculadora, por outro lado, 10 dos futuros professores ressignificaram seus posicionamento de maneira afirmativa ao uso de calculadora nesta última tarefa. Um deles passou a concordar completamente, como podemos notar nesse trecho: "Após a exposição da aula de hoje, vejo que nesta perspectiva, deve-se utilizar a calculadora, tendo em vista que é uma ferramenta que ainda é desconhecida pelo professor" (Futura Professora E). É possível notar que essa futura professora conseguiu ampliar sua visão dos possíveis alcances de se utilizar a calculadora, e ela prosseguiu: "É a oportunidade da criança conhecer essa ferramenta e até mesmo ensinar alguém que não conhece ainda as funções".

Neste mesmo grupo, 9 futuros professores passaram a considerar o uso interessante, porém apresentaram algumas recomendações para o uso como o Futuro Professor P. que retrata esses posicionamentos: "o uso da calculadora nos anos iniciais tem que estar adaptado à atividade, a calculadora não 'emburrece o aluno' pois o pensamento e raciocínio vem antes da digitação na calculadora". Notamos que em algumas opiniões os participantes manifestaram a preocupação com a utilização generalizada na sala de aula, como nesse fragmento da Futura Professora R: "Porém, usar o objeto em todas as aulas não seria adequado, haja vista que o aluno precisa desenvolver $\mathrm{e}$ aprender as habilidades matemáticas sem o auxílio deste aparelho".

A tabela 3 contém informações sobre o subgrupo dos futuros professores que inicialmente foram classificados como consideram o uso interessante, mas com ressalvas:

Tabela 3 - Futuros professores que inicialmente foram classificados como consideram o uso interessante, mas com ressalvas

\begin{tabular}{cc}
\hline Opinião Final & Quantidade \\
\hline Totalmente a favor & 08 \\
Totalmente contra & 00 \\
Consideram o uso interessante, mas com ressalvas & 08 \\
Total & 16 \\
\hline
\end{tabular}

Fonte: Elaborado pelas autoras

Referente às opiniões em que não houve ressignificações 8 futuros professores mantiveram suas opiniões iniciais, sobre o uso com ressalvas. Alguns desses relataram preocupação no uso equilibrado da calculadora como podemos ver no trecho: "pude perceber que a calculadora, assim 
como o cálculo escrito, é uma ferramenta importante e necessária para as aulas de matemática nos anos iniciais do Ensino Fundamental, porém não deve haver um foco nesta competência, como qualquer outra, deve existir uma dosagem de cada meio" Futura Professora M.

Por fim, outros 8 futuros professores classificados inicialmente no grupo "c" reavaliaram de maneira positiva o uso de calculadora nos Anos Iniciais do Ensino Fundamental, passaram a concordar com a utilização dessa ferramenta. A Futura Professora I. apresentou argumentos de que ampliou sua visão sobre o tema: "a partir do que foi apresentado ficou ainda mais claro que a calculadora pode e deve ser utilizada no processo de aprendizagem matemática, como um excelente suporte para o desenvolvimento das competências de cálculo, para além do simples uso e só cálculo escrito".

Gostaríamos de enfatizar os casos de futuros professores que ressignificaram suas reflexões iniciais, deste modo ocorreram 21 casos de futuros professores que alteraram seus posicionamentos referentes ao uso de calculadora nos Anos Iniciais do Ensino Fundamental nas aulas de matemática. Além disso, em alguns textos podemos notar algumas reflexões referente às famílias dos estudantes, que também foi discutido inicialmente, por exemplo: "acho que as famílias precisam saber sobre as várias atividades possíveis com a calculadora e que, quando souberem, também serão a favor" (Futura Professora F.).

Nessa mesma perspectiva, a Futura Professora D. que na fase inicial teve o seguinte posicionamento: "como mãe, se minha filha usasse ou tivesse permissão e incentivo da professora para usar a calculadora em detrimento ao método propedêutico matemático, eu não gostaria. Penso que ela se acomodaria e em casos de falta de uma calculadora ela não saberia se virar" na fase final", escreveu o seguinte depoimento: "Agora como mãe eu gostaria que minha filha tivesse esse contato" (Futura Professora D.)

\section{ALGUMAS CONSIDERAÇÕES}

Consideramos que as possibilidades e benefícios do uso da calculadora em sala de aula são inúmeros e que seu bom uso não prejudica o desenvolvimento do estudante, mas gostaríamos de ressaltar que ainda é um grande desafio para o curso de formação de professores, que atuarão junto aos estudantes dos Anos Iniciais do Ensino Fundamental, despertar o interesse pela Matemática e desmistificar o uso da calculadora na sala de aula.

Pudemos investigar as concepções dos futuros professores, que em grande maioria eram totalmente contrários ao uso da calculadora ou consideravam o uso interessante, mas com ressalvas, e principalmente propiciar momentos de estudo, reflexão e prática que contribuíram para uma mudança significativa nessas concepções. Analisamos que conseguimos atingir nossos objetivos no estudo, devido às ressignificações apresentadas pelos estudantes, e neste trabalho de apresentar a proposta didática e as reflexões dos participantes.

Concluímos junto aos futuros professores que é essencial que a escola ofereça ao estudante contato com as tecnologias e ajude-os a trabalhar com elas. Porém, ressaltamos que os estudantes dos Anos Iniciais do Ensino Fundamental devem saber calcular independentemente das máquinas e acreditamos que o bom contrato didático é fundamental para que os mesmos saibam reconhecer os momentos necessários para utilizá-la.

Esperamos que os futuros professores possam começar em breve um trabalho diferente em sala de aula e possam se juntar a nós, na defesa do uso da calculadora junto aos estudantes dos Anos Iniciais do Ensino Fundamental. Reforçamos também a necessidade de informar e formar as famílias a respeito do uso das calculadoras, para que possam apoiar o trabalho nas aulas e o trabalho do professor. Por fim, almejamos que este trabalho inspire novas pesquisas e investigações no âmbito da formação de professores e na sala de aula desse nível da educação básica.

\section{AGRADECIMENTOS}

Agradecemos o apoio da FAPEMIG (Fundação de Amparo à Pesquisa de Minas Gerais) e a Pró Reitoria de Pesquisa de Universidade Federal de Minas Gerais (PRPQ). 


\section{REFERÊNCIAS}

BOGDAN, R. C.; BIKLEN, S. K. Investigação qualitativa em educação: uma introdução à teoria dos métodos. (Coleção Ciências da Educação). Portugal: Porto Editora, 1994.

BRASIL. Ministério da Educação e do Desporto. Secretaria de Educação Fundamental. Parâmetros Curriculares Nacionais: matemática. Brasília: MEC/ SEF, 1997.

FERNANDES, S.H.A.A. et al. Ver e ouvir a Matemática com uma calculadora colorida e musical: estratégias para incluir aprendizes surdos e aprendizes cegos nas salas de aulas. In: PLETSCH, M. D.; DAMASCENO, A. R. (Org.). Educação Especial e inclusão escolar: reflexões sobre o fazer pedagógico. Seropédica/RJ: EDUR, 2011, p. 97-111.

IMENES, L. M. P.; LELLIS, M. Matemática. São Paulo. Scipione, 1997.

LEANDRO, E. G. Polikalc: a criação de um objeto de aprendizagem para o ensino de cálculos aritméticos no ensino fundamental., 2014. Trabalho de Conclusão de Curso (Monografia) .- Universidade Federal de Lavras, 2014.
LOPES, A. J.; RODRIGUEZ, J. G. Metodologia para o ensino da aritmética: competência numérica no cotidiano. São Paulo: FTD, 2009.

. Matemática do cotidiano: matemática. $1 .^{a}$ ed. São Paulo: Scipione, 2014.

MATEMÁTICA INCLUSIVA. Rumo a educação matemática inclusiva. (portal). Aplicativos: MusiCALcolorida. Anhanguera, Programa de Pós-Graduação em Educação Matemática. 2002. Disponível em: $<$ http://www.matematicainclusiva.net.br/aplicativo. php>. Acesso em: 02 nov 2017.

SELVA, A. C. V.; BORBA, R. E. S. R. O uso da calculadora nos anos iniciais do ensino fundamental. (Coleção Tendências em Educação Matemática). Belo Horizonte: Autêntica, 2010.

VAN DE WALLE, J. Matemática no ensino fundamental: formação de professores e aplicação em sala de aula. Tradução de Paulo Henrique Colonese. 6ed. Porto Alegre: Artmed, 2009. 